\title{
Obituaries
}

\section{Professor John Wing, CBE}

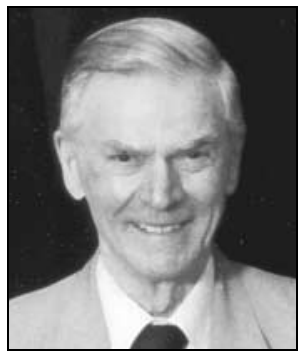

Formerly Professor of Social Psychiatry, Institute of Psychiatry, London

John Wing was born on 22 October 1923. He joined the Fleet Air Arm at the height of the Second World War, and found himself navigating planes engaged in bombing raids over

Scandinavia. It was often necessary to land on the mother ship mid-ocean and John possessed the courage and skill to bring this dangerous operation to a successful conclusion.

After the war, he trained at University College London, where he met his future wife, Lorna. After completion of his training, John immersed himself in the problems of rehabilitating people with schizophrenia, who were languishing in mental hospitals. In 1960 he produced his PhD thesis and a year later his MD thesis. During this time his collaboration with George Brown produced the seminal book Institutionalism and Schizophrenia, which gave the world its most definitive description of social factors that favoured the production of negative symptoms in schizophrenia, and those associated with the reverse.

John was a man with a soft heart and a steely determination. He studied and sympathised with people of all sorts and ages in the course of improving the lots of both patients and their families who were receiving inadequate treatment. At parties in his home, catered by Lorna, he would arrange table tennis tournaments, and if pressed, would, with some diffidence, take up his guitar and play.

He was keen to adopt technical advances and in the precomputer era would bring a hand-held mechanical calculator to meetings and perform instant calculations by cranking the handle. In meetings he was not voluble but when necessary would apply his keen intelligence to problems and cut through the waffle. John's intellectual acuity is remembered from seminars he gave in the early 1970s at the Institute of Psychiatry. For instance, he would terrify the assembled Maudsley registrars by asking if anyone would defend the medical model. No one would offer, and he would lay out his views on the nature of psychiatric disorders, of psychiatric classification, and of diagnosis. In doing so he revealed his debt to Karl Popper, and the way he had adapted Popper's thinking to the needs of psychiatric research. His central role in the development of the Present State Examination was driven by these ideas.

As Director of the Medical Research Council's Social Psychiatry Research Unit, he oversaw the production of numerous measuring instruments without which much social research across the world could not have been done, and he produced the influential epidemiological study of mental disorders in Camberwell, as well as overseeing the Maudsley Hospital's first steps to establishing a community mental health service. He was appointed as the first director of the
Royal College of Psychiatrists' Research Unit on his retirement in 1989. Over the next 7 years, he laid the foundations for a thriving work programme that continues to this day and which has had a substantial influence on national policy and on improving the quality of mental healthcare in the UK. He was elected to the Honorary Fellowship of the College in 1996.

In 1994, he finished work commissioned by the Department of Health to develop the Health of the Nation Outcome Scales (HoNOS). The Scales are probably now the most widely used system for monitoring the outcomes for people with severe mental illness. They have been translated into many languages and a number of countries have mandated their use as part of monitoring of routine care. John led the development of the College's first clinical practice guideline using state-of-the-art methods for review and grading of the evidence. The guideline on the management of violence in mental healthcare settings was published 2 years before the establishment of the National Institute for Health and Clinical Excellence (NICE) and placed the College in a strong position to host the National Collaborating Centre for Mental Health, which continues to produce clinical practice guidelines that are considered the world's best.

John loved gardening. In Sussex he had 2-3 acres of garden, which he completely redesigned, making flowerbeds and paths between them, and planting some beautiful trees, bushes and flowers. He planned it all without any help and the result was a tribute to his artistic eye.

John had a cat, who was a mighty hunter and was especially attached to him. The cat used to place all the trophies he brought in through the cat flap (mice, rats, even the occasional rabbit) underneath John's chair at the dining table. In this, the cat resembled his former junior colleagues, one of whom writes: 'As a naturally quiet man, the most salient way in which John transmitted his intellectual legacy was by commenting on draft papers. One's best efforts would come back with annotations and corrections that would provide sudden insights and a requirement to reconsider the architecture of one's own thinking'.

Professor John Wing died on 18 April 2010.

doi: $10.1192 /$ pb.bp.110.032557

Jim Birley

\section{Professor Carlo Lorenzo Cazzullo}

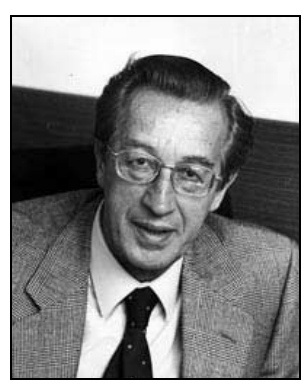

\section{Formerly Professor of Psychiatry, Milan, Italy}

Professor Carlo Lorenzo Cazzullo, Emeritus Professor of Psychiatry at the University of Milan, died on 4 May 2010, aged 95. He became Professor of Psychiatry in 1959, the first to hold such a title in Italy. With his appointment, psychiatry was not only to become officially recognised as a medical subject other than neurology but also as a separate medical specialty. It was later to become a core 
subject by law in 1976. The relevant legislation known as Legge no 238 bears his name.

As head and founder (in 1960s) of the Istituto di Psichiatria in Milan, Professor Cazzullo generated a great many strands of scientific research, the Institute being among the first in Italy to establish international links with major research centres across the world and also adopt a scientific methodology that followed international practice. In addition to the Instituto di Psichiatria, Professor Cazzullo was also the founder of the Centre for the Study of Multiple Sclerosis of the University of Milan in 1963, and he retained an interest in this condition during his entire career.

He was born in Gallarate in the north of Italy on 30 January 1915. He gained an honours degree in medicine in 1945 after first training as an accountant. He began his career under Professor Carlo Besta, founder of the Institute of Neurology in Milan, a lasting influence.

In 1947, he went to the USA to train first at New York's Rockefeller Institute, where he undertook research in neurophysiology under Dr H. Gasser and Dr Lorente de No, and subsequently in 1948 at the Columbia University Institute of Psychiatry, where he undertook research in neuropathology under Professor A. Ferraro and Dr N. Lewes. In 1949, he went to Montreal Neurological Institute to study with Dr W. Penfield and $\mathrm{Dr} \mathrm{H}$. Jasper as a Visiting Investigator.

Professor Cazzullo was a great clinician and a brilliant teacher. He was a great advocate of the multifactorial approach in terms of causation and should be regarded in retrospect as probably the first exponent in Italy of the biopsychosocial model invented in England in the 1970s, which was to influence an entire generation of psychiatrists and which he used to teach relentlessly.

He rejected simplistic explanations based on a single cause when such explanations were fashionable in the 1970s Italy, especially with regard to the origins of schizophrenia, which he considered to be juvenile. When the anti-psychiatry movement gained ground in Milan and in the rest of the country in the early 1970s and seemed unstoppable, he successfully demolished their arguments in public speeches.

The Institute was in turn a very broad church where any serious psychiatric viewpoint was equally represented in the Institute's sections and departments. Opportunities for debate were endless and the place was a magnet for ambitious psychiatric trainees of different theoretical orientation from the beginning. His pupils were all in time to take up senior positions in Italy.

Professor Cazzullo also ought to be remembered as having a unique gift for fostering very young talent, whom he launched early on the international stage. Papers from the Milanese School regularly appeared in English in all the major international journals yet members of his research group, who were frequent speakers at national and international conferences, were often strikingly young.

He was a prolific author. His original studies include the first immunological study in the English-speaking literature of the human leukocyte antigen (HLA) system in schizophrenia in 1974 and an important study of N1-NM (N1-methylnicotinamide) as a biological marker of primary affective disorder also published in English in 1976, as well as key papers in psychopharmacology, self-harm and higher nervous activity, particularly evoked potentials. His main interest, however, was always to be the study of serious mental illness, especially schizophrenia, where he favoured an integrative approach which was to include the study of the family.

Professor Cazzullo was not a psychotherapist but believed fundamentally in the importance of the doctor-patient relationship, inviting Dr Michael Balint to Italy and introducing Balint groups in Italian psychiatry for the first time. He was also the first to admit psychiatric patients to a general hospital ward, some 15 years before the Legge 180 of 1978. This legislation, better known as Basaglia's Law, was to finally determine the closure of the mental hospitals in Italy.

Like Basaglia, he always took the view that the stigma of mental illness in Italian society needed to be reduced and that psychiatry had a responsibility to achieve this. Unlike Basaglia, however, he took the then unfashionable view that this could be achieved by providing information about mental illness to people, and was active at every level in this regard throughout his career. Unlike Basaglia, he also took the view that if psychiatry were not to be an instrument of social control, it had to have its roots firmly in academic research.

Professor Cazzullo was elected President of the Societa' Italiana di Psichiatria in 1968, were he was to continue serving for many years, and President of the Societa' Italiana di NeuroPsicofarmacologia, which he founded in 1963. He also held a number of prestigious appointments with the World Psychiatric Association, the World Health Organization and the EEC, subsequently known as the European Union. He was to collect a vast number of honours and awards throughout his distinguished career, including the Albert Schweitzer International Gold Medal for the Humanisation of Medicine, which he was awarded by the Polish Academy of Medicine in 1996. He was a Corresponding Editor of the British Journal of Psychiatry.

In 1976, he visited China under the auspices of the Italian Foreign Office and in 1977 he was offered (by Professor $\mathrm{H}$. Gantt) the post of Director and Head of the Department of Psychiatry at Johns Hopkins University, Baltimore, which he did not accept.

The Istituto di Psichiatria in Milan had a base in the Ospedale 'Paoli Pini', a mental hospital in a small suburb on the outskirts of Milan called Affori, which was the main centre. It was also, however, to acquire a base in the Padiglione di Guardia II in the Ospedale Policlinico, a large university general hospital in the centre of Milan. This was later to become a leading centre for the study of self-harm and a major driver for liaison psychiatry in Milan. To both trainees and trainers, the main centre was affectionately known as Affori.

I have been privileged to train in Milan under Professor Cazzullo in the early 1970 s before moving to Britain. I can well remember arriving at Affori in 1972 as a young postgraduate trainee and recognising immediately that this was a very special place. I was to spend 4 exceptional years at Affori, where I also had the opportunity of studying at the nearby Istituto di Neuropsichiatria Infantile, which was ran by his second wife, Adriana Guareschi-Cazzullo, herself an esteemed professor of child neuropsychiatry. This is where I first became acquainted with Kleinian psychoanalysis, particularly the work of $\mathrm{Dr} \mathrm{H}$. Rosenfeld, which was to be instrumental in my subsequently coming to Britain.

Training under Professor Cazzullo demanded very high standards but he could be close to trainees and very supportive. When I told him of my intention to come and train 
in London, he was visibly disappointed. However, he also recommended immediately that I apply to train at the Royal Free Hospital, which he said he had visited the year before.

I remember him saying that he had been very impressed by the newly built mother and baby unit in the general ward, clearly another example of the type of innovation which he greatly admired.

Professor Cazzullo did not suffer fools gladly. He was a great inspirational figure and a towering giant in Italian psychiatry. He had enemies and friends like all those who make history. He was above all a moderniser. Psychiatrists whose lives and careers he helped to shape and who were touched by his incredible intellect will always miss him dearly.

Giuseppe Spoto

doi: 10.1192/pb.bp.110.032565

\section{Dr Ronald Arthur Sandison}

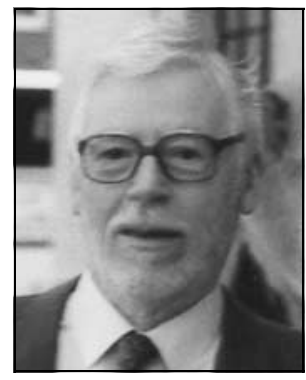

\section{Formerly Honorary Consultant, Southend, Ledbury}

Sandison was born in 1916, in the Shetland Isles 200 miles north of Scotland. He started his pre-clinical studies in 1934 and qualified MBBS (Lond) in 1940. During the war he served in the RAF as a physiologist studying altitude effects on Spitfire pilots. In 1945 he became a trainee psychiatrist at Warlingham Park Hospital, Surrey. There, fascinated by the dreams patients experienced during insulin coma therapy, he developed an interest in Jungian psychology.

Ronald moved to Powick Hospital in Worcestershire in 1951 as a consultant and began improving the dilapidated hospital. In 1952, while on a tour in Switzerland, he serendipitously visited the Sandoz laboratories and met Albert Hofmann, the discoverer of the experimental compound lysergic acid diethylamide (LSD). This remarkable drug is virtually inert physiologically, physically non-toxic and not addictive, yet immensely powerful at minute doses. Sandison was fascinated by what he saw and returned to the UK with 100 vials of the drug.

At this stage, LSD had only been used on a handful of people, but there was a growing theoretical basis for using it as an adjunct for psychotherapy. Impressed by LSD's effects on altering human consciousness, Sandison began using infrequent low doses with his patients 'stuck' in various stages of their psychoanalysis. He noticed immediate positive results, even in cases of severe, unremitting illness. The drug appeared to produce hallucinations of a dream-like quality, which directly reflected the patient's unconscious mind, allowing them to relive forgotten memories.
In 1954, the same year that Aldous Huxley published The Doors of Perception, Sandison published a paper with his colleagues Spencer and Whitelaw describing LSD-assisted psychotherapy on 36 patients in which the treatment was overwhelmingly positive and without adverse effects.

In 1955 he developed the world's first purpose-built LSD unit in the grounds of Powick, where up to five patients could receive LSD simultaneously, in rooms equipped with a couch, a chair and a blackboard for drawing emerging images.

Dr Sandison and his team oversaw the sessions and came together with the patients for a group session at the end of the day.

The Powick model became the blueprint used throughout Britain and the world for LSD treatment and, at this point in history, LSD was hoped to be 'the next big thing' in modern psychiatry. In 1955 Sandison addressed the American Psychiatric Association about his work. Then, in 1961, he chaired the Royal Medico-Psychological Association meeting, which was devoted entirely to LSD therapy.

In 1964, after 12 years dedicated to seeing thousands of patients through LSD psychotherapy, Sandison ended his work at Powick and took a job at Knowle hospital near Southampton. The drug was becoming misused widely outside the medical profession and, like many psychiatrists at the time, Sandison chose to distance himself from the growing negative media attention. Also frustrated by psychiatry's increasing dependence on daily-prescribed psychotropic drugs he found himself gravitating towards psychotherapy.

He joined the Group Analytic Society and, for the next 10 years, ran group therapy workshops, developed a therapeutic community and ran a day hospital. Dedicated to keeping psychotherapy firmly embedded in the National Health Service, he encouraged registrars to take a diploma in psychotherapy and recruited medical students to the newly formed Southampton Medical School.

Between 1975 and 1982, Sandison returned to his native Shetland and overhauled the threadbare psychiatric services there. For the remainder of his working life he used his psychotherapy skills in the field of psychosexual medicine and family planning at the Margaret Pyke centre in London, before retiring in 1992.

Despite his broad career, Ronald Sandison will be remembered worldwide for his pioneering work with LSD. He considered many psychiatric drugs to, at best, mask symptoms - in stark contrast to LSD, which, when used in a controlled environment, allowed material to be worked through with psychotherapy. He loathed the recreational use of drugs, preferring his own term 'psycholytic' ('mind-loosening') to the heavily popularised word 'psychedelic'.

He was a deeply compassionate doctor, not afraid to watchfully push the boundaries of tradition to explore potential new benefits for his patients. A true pioneer in medicine, he will be missed.

He died peacefully on 18 June 2010.

Ben Sessa

doi: 10.1192/pb.bp.110.032540 